\title{
Correction to: Transcriptome analysis of flowering genes in mango (Mangifera indica L.) in relation to floral malformation
}

\author{
Ashok Yadav ${ }^{1} \cdot$ Pawan K. Jayaswal $^{2} \cdot$ K. Venkat Raman ${ }^{2} \cdot$ Bhupinder Singh $^{3} \cdot$ Nagendra K. Singh $^{2} \cdot$ \\ K. Usha ${ }^{1}$ (iD
}

Published online: 22 January 2020

(C) Society for Plant Biochemistry and Biotechnology 2020

\section{Correction to: Journal of Plant Biochemistry and Biotechnology https://doi.org/10.1007/ s13562-019-00541-z}

Unfortunately, Fig. 5a, b is overlapped in the online publication of the article. Hereby, the correct figures are given below.
The original article has been updated accordingly.

Publisher's Note Springer Nature remains neutral with regard to jurisdictional claims in published maps and institutional affiliations.

The original article can be found online at https:// doi.org/10.1007/s13562-019-00541-z.

\section{K. Usha}

kalidindi.usha3@gmail.com

1 Division of Fruits and Horticultural Technology, IARI,

New Delhi, India

2 National Research Centre for Plant Biotechnology,

New Delhi, India

3 Centre for Environment Science and Climate Resilient

Agriculture, IARI, New Delhi, India 
Fig. 5 a Differentially expressed up-regulated flowering genes in six possible combinations $\{\mathrm{HB}-1$ versus MB-1 (red color), HB-1 versus MB-2 (blue color), HB-1 versus MB-3 (pink color), HB-2 versus MB-1 (light green color), HB-2 versus MB-2 (purple color), HB-2 versus MB-3 (sky blue color) $\}$ having $\log _{2} \mathrm{FC} \geq 2$, b differentially expressed downregulated flowering genes in six possible combinations $\{\mathrm{HB}-1$ versus MB-1 (red color), HB-1 versus MB-2 (blue color), HB-1 v MB-3 (pink color), HB-2 versus MB-1 (light green color), HB-2 versus MB-2 (purple color), HB-2 versus MB-3 (sky blue color) $\}$ having $\log _{2}$

$\mathrm{FC} \leq-2$ (color figure online)
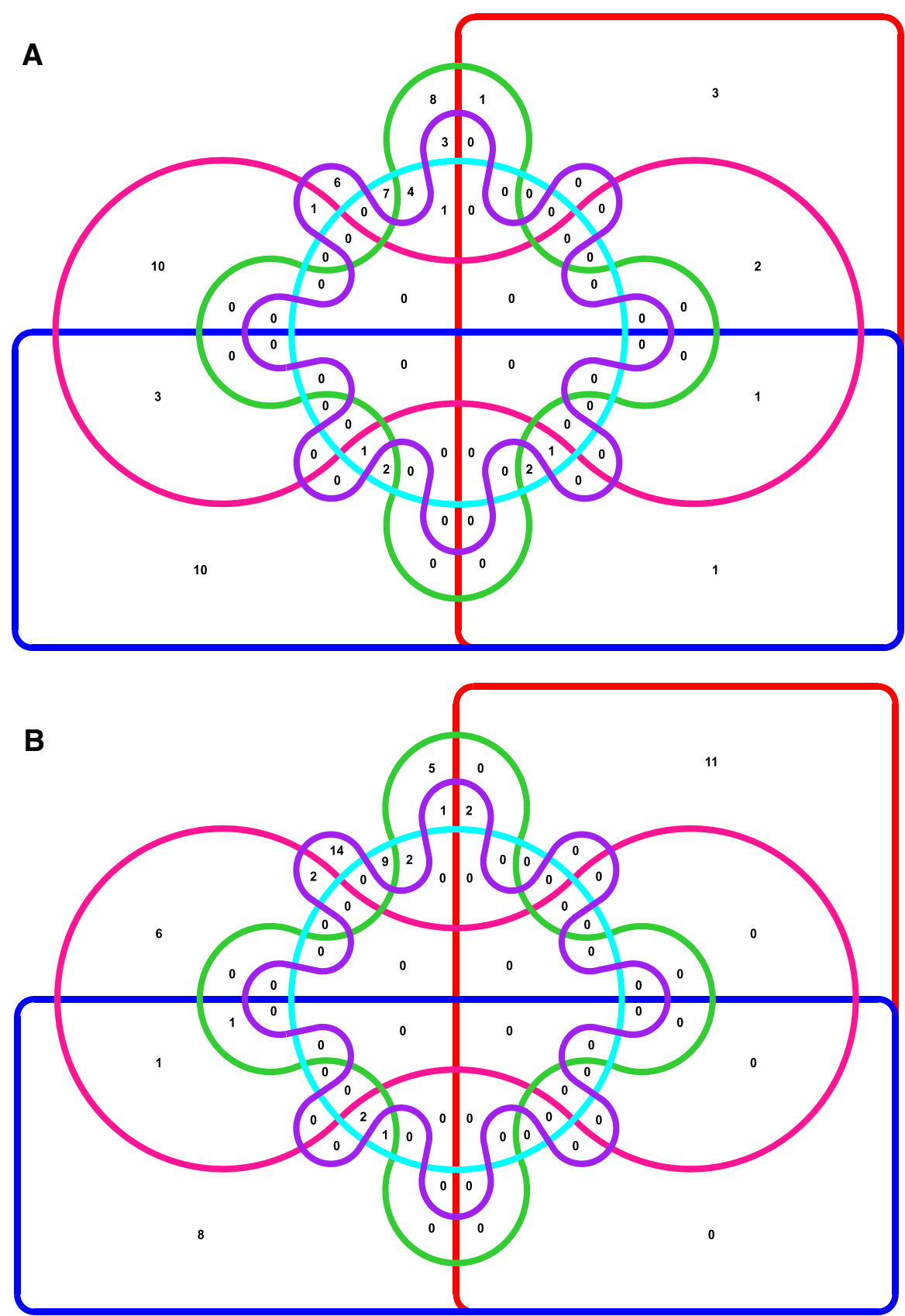